\title{
Therapy-relevant aberrant expression of MRP3 and BCRP mRNA in TCC-/SCC-bladder cancer tissue of untreated patients
}

\author{
MONA RADY ${ }^{1}$, MARWA MOSTAGEER ${ }^{1,2}$, JAN ROHDE $^{1,3}$, ASHRAF ZAGHLOUL $^{4}$, RUTH KNÜCHEL-CLARKE $^{5}$, \\ SHADY SAAD $^{1,8}$, DEENA ATTIA ${ }^{1}$, LAILA MAHRAN ${ }^{1 *}$ and HILDE SPAHN-LANGGUTH ${ }^{1,6,7}$ \\ ${ }^{1}$ Faculty of Pharmacy and Biotechnology, German University in Cairo, New Cairo, Egypt; ${ }^{2}$ AFFiRiS AG, Vienna, Austria; \\ ${ }^{3}$ Rhein-Minapharm Biogenetics, $10^{\text {th }}$ of Ramadan City; ${ }^{4}$ Department of Surgical Oncology, National Cancer \\ Institute, Cairo University, Cairo, Egypt; ${ }^{5}$ Institute of Pathology, University Hospital, Aachen, Germany; \\ ${ }^{6}$ Institute of Pharmaceutical Sciences, Department of Pharmaceutical Chemistry, University of Graz, Graz, Austria
}

Received September 29, 2016; Accepted April 3, 2017

DOI: $10.3892 /$ or.2017.5695

\begin{abstract}
Multidrug resistance (MDR) is a critical factor, which results in suboptimal outcomes in cancer chemotherapy. One principal mechanism of MDR is the increased expression of ATP-binding cassette (ABC) transporters. Of these, multidrug resistance-associated protein 3 (MRP3) and breast cancer resistance protein (BCRP) confer MDR when overexpressed in cancer cell lines. We measured the mRNA expression of MRP3 and BCRP in primary untreated bladder cancer specimens using reverse transcription-quantitative PCR (RT-qPCR) in comparison to normal bladder tissue. The MRP3 and BCRP expression in the two major histotypes of bladder cancer; transitional cell carcinoma (TCC; urothelial type of bladder cancer) and squamous cell carcinoma (SCC; 'Schistosoma-induced' bladder cancer) were compared. Furthermore, the association between MRP3 and BCRP expression and tumor grade and stage were investigated. MRP3 mRNA expression in bladder cancer specimens was increased $\sim 13$-fold on average compared to normal bladder tissue $(\mathrm{n}=36, \mathrm{P}<0.0001)$. BCRP mRNA expression was decreased in bladder cancer specimens to $\sim 1 / 5$ on average, compared to normal bladder tissue $(n=38, P<0.0001)$. TCC showed significantly increased MRP3 mRNA expression compared to SCC of the bladder $(\mathrm{P}<0.0001)$. BCRP mRNA
\end{abstract}

Correspondence to: Dr Mona Rady, Faculty of Pharmacy and Biotechnology, The German University in Cairo - GUC, New Cairo City - Main Entrance Al Tagamoa Al Khames, New Cairo 11835, Egypt

E-mail: mona.rady@guc.edu.eg

Present addresses: ${ }^{7}$ IMPP, Grosse Langgasse 8, D-55116 Mainz, Germany; ${ }^{8}$ Institute of Biochemistry, ETH Zurich, Zurich, Switzerland

*Deceased

Key words: multidrug resistance, MRP3/ABCC3, BCRP/ABCG2, bladder cancer, transitional cell carcinoma, squamous cell carcinoma expression was similar in TCC and SCC of the bladder $(\mathrm{P}=0.1072)$. The increased MRP3 mRNA expression was not related to bladder tumor grade $(\mathrm{P}=0.3465)$ but was, however, significantly higher in superficial than in invasive bladder tumors $(\mathrm{P}=0.0173)$. The decreased expression of $\mathrm{BCRP}$ was not related to bladder tumor grade $(\mathrm{P}=0.1808)$ or stage $(\mathrm{P}=0.8016)$. The current data show that bladder cancer is associated with perturbed expression of MRP3 and BCRP. Representing drug resistance factors, determining the expression of these transporters in native tumors may be predictive of the outcome of chemotherapy based-treatment of bladder cancer.

\section{Introduction}

Worldwide, bladder cancer is the ninth most common cause of cancer for both sexes combined. The highest recorded annual incidence and mortality rates of bladder cancer are that found in Egypt (1-3). TCC of the urinary bladder is the major histological cell type of non-Bilharzial bladder cancer, hence is the major histological cell type in Western countries. SCC, the major histological cell type of bilharzial bladder cancer represents less than $5 \%$ of the cases of bladder cancer in Western countries (2). In Egypt, both SCC and TCC are predominant (4) where schistosomiasis/Bilharziasis as well as increased smoking and exposure to environmental carcinogens prevail.

ABC transporters constitute a superfamily of 49 transport proteins, organized into seven subfamilies, ABCA - ABCG, on the basis of their sequence homology and domain organization $(5,6)$. ABC transporters play an important role in limiting cellular exposure to toxic xenobiotics and carcinogens by actively pumping their substrates out of the cells. In cancer cells, overexpression of $\mathrm{ABC}$ transporters leads to decreased cellular drug accumulation below cytotoxic levels (7). Thus, ABC transporters contribute to MDR in cancer cells. Historically, the first of the human $\mathrm{ABC}$ transporters to be identified as a multidrug resistance protein was the P-glycoprotein (MDR1/ABCB1). In addition, the multidrug resistance-associated protein (MRP/ABCC) family of ABC transporters is included, which consists of nine proteins, eight of which have been determined to function as cellular resistance factors for various anticancer agents (8). The MRP1/ABCC1 is the founding member of the 
MRP family of $\mathrm{ABC}$ transporters and is nearly ubiquitously expressed, while the MRP2/ABCC2 is present mainly in the canalicular membrane of hepatocytes. The third member of the MRP membrane transporter family is the MRP3/ABCC3. The MRP3 shares a high degree of amino acid homology with MRP1 $(58 \%)(9-11)$ and is a $170 \mathrm{kDa}$ protein with 18 transmembrane domains encoded by the ABCC3 gene (chromosome 17q21.3). While in the liver (basolateral membrane of cholangiocytes and hepatocytes), pancreas, and the intestinal tract (basolateral membrane of enterocytes; small, intestine, and colon) MRP3 is expressed at high levels (9-11), the urinary bladder shows lower, yet considerable levels of MRP3 mRNA (12). With respect to its physiological function, MRP3 is involved in the transport and, hence, regulation of bile salts, transports leukotrienes as well as glucuronic acid conjugates and glucosides. In MRP3transfected cancer cell lines it was demonstrated that MRP3 has the ability to transport certain classes of cytotoxic anticancer agents (21-23), mainly drug compounds with a molecular weight above $0.45-0.5 \mathrm{kDa}$ as well as drug or metabolite conjugates. Therefore, increased MRP3 expression during carcinogenesis implies possible involvement of MRP3 in the acquisition of an $a b$ initio drug-resistant phenotype in some tumors.

A second unique $\mathrm{ABC}$ transporter is the breast cancer resistance protein (BCRP/ABCG2). The BCRP transporter is a $72 \mathrm{kDa}$ 'half transporter' encoded by the $A B C G 2$ gene, consisting of six transmembrane domains and functions as a homodimer or homotetramer. It belongs to the $\mathrm{G}$ subfamily of $\mathrm{ABC}$ reverse half transporters which functions by forming a homodimer or homotetramer bridged by disulfide bonds $(7,13)$. The mRNA and protein of BCRP were detected at the transitional epithelium of normal bladder [(7) and (14), respectively]. This suggests the protective role BCRP plays by actively effluxing toxic endobiotics and xenobiotics out of cells. In general, BCRP is expressed in hematological malignant neoplasms and solid tumors. BCRP is involved in intestinal, biliary, and renal secretion of substrates and appears to be protecting fetus and brain from toxins. The group of substrates includes dietary and endogenous compounds (e.g., flavonoids, porphyrins, estrones, bile acids) showing an overlap in substrate specificity with the hydrophobic-substrate-oriented MDR1, yet additionally transporting hydrophilic conjugated organic anions with high affinity, and apparently increasing the overall barrier function (15).

Few studies have examined the expression of MRP3 or BCRP in native (untreated) cancer tissues. Consequently, the potential role these transporters play in the pathophysiology of cancer and/or clinical MDR is still unknown (16). Considering the role BCRP and MRP3 might play as either cytoprotectants or drug resistance factors we investigated their mRNA expression in primary untreated bladder tumors of the two major histotypes; TCC and SCC of the bladder. The mRNA levels of the transporters were compared in TCC and SCC of the bladder and correlated to the disease state of the patient with respect to the invasiveness and degree of differentiation of the bladder tumor.

\section{Materials and methods}

Tumor specimen acquisition and preservation. The use of all human tissue was approved by the local ethics commit- tees of the National Cancer Institute (NCI), Cairo University and the German University in Cairo, and informed consents were obtained in accordance with the Declaration of Helsinki. A total of 44 biopsies from patients with primary untreated bladder tumors were collected from the endoscopy unit, National Cancer Institute-Cairo, Egypt after obtaining informed consent. Immediately after transurethral resection, specimens were submerged in approximately 10 volumes of RNAlater RNA Stabilization Reagent (Qiagen). All specimens were less than $0.5 \mathrm{~cm}$ thick for effective RNA stabilization. Specimens were incubated overnight at $4^{\circ} \mathrm{C}$ before storage at $-20^{\circ} \mathrm{C}$ until RNA extraction process started. Before RNA isolation, each specimen was cut longitudinally into two equal fragments. One fragment was used for RNA isolation and subsequent gene expression analysis. The other fragment was used for preparation of hematoxylin and eosin stained paraffin embedded tissue sections for histopathological examination. Specimens were washed two times for $15 \mathrm{~min}$ in phosphate buffered saline (PBS) before preparation of hematoxylin and eosin stained paraffin embedded tissue sections. In addition, routine pathology examination reports for those patients were obtained from the National Cancer Institute for further confirmation of diagnosis. The 1997 TNM stage and the 1973 WHO grade classifications were used.

Total RNA isolation and cDNA synthesis. Total RNA was isolated from $30 \mathrm{mg}$ RNA-stabilized bladder cancer specimens using RNeasy Plus Mini kit (Qiagen) according to the manufacturer's directions. Tumor sample total RNA was eluted in $40 \mu \mathrm{l}$ nuclease-free water and stored at $-80^{\circ} \mathrm{C}$. Total RNA integrity and purity were electrophoretically verified by ethidium bromide staining and by $\mathrm{A}_{260} / \mathrm{A}_{280} \mathrm{~nm}$ absorption ratio $>1.85$. Total RNA $(5 \mu \mathrm{g})$ was reverse transcribed using Sprint $^{\mathrm{TM}}$ PowerScript $^{\mathrm{TM}}$ PrePrimed Single Shots kit (Clontech Laboratories, Inc.) according to the manufacturer's directions in a final reaction volume of $20 \mu \mathrm{l}$.

$R T-q P C R$. The mRNA levels of BCRP and MRP3 were measured by RT-qPCR based on SYBR Green I chemistry and quantified using MX3005 $\mathrm{P}^{\mathrm{TM}}$ quantitative real-time PCR system (Stratagene). In addition, the mRNA levels of a reference gene, aminoacyl tRNA synthetase complexinteracting multifunctional protein 1 (AIMP1/EMAP) was measured and used to normalize the mRNA levels of the BCRP and MRP3. The primer pairs for the BCRP, MRP3, and AIMP1 (Table I) were as previously described (17-19), and purchased from Metabion $\mathrm{GmbH}$. The forward and reverse primers were run in a BLASTn for aligning their sequences against human transcript database to ensure that the primers do not coamplify homologous transcripts. Primers amplify across an intron/exon boundary or span large introns, thereby preventing amplification of residual genomic DNA. RT-qPCR was performed in triplicate reactions using Power SYBR Green PCR Master Mix (Applied Biosystems) for BCRP expression analysis and QuantiFast SYBR Green PCR Master Mix (Qiagen) for MRP3. Each reaction mixture contained $12.5 \mu 1$ Master Mix, $1 \mu 1$ ( $\sim 50 \mathrm{ng})$ tumor sample cDNA as a template, $300 \mathrm{nM}$ forward and reverse primers for BCRP and MRP3 and $200 \mathrm{nM}$ forward and reverse primers for AIMP1 in a final reaction volume 
Table I. Sequences of primer pairs.

\begin{tabular}{lclccc}
\hline $\begin{array}{l}\text { Gene } \\
\text { name }\end{array}$ & $\begin{array}{c}\text { GenBank } \\
\text { accession } \\
\text { number }\end{array}$ & \multicolumn{1}{c}{$\begin{array}{c}\text { 5' to 3' Primer sequence } \\
\text { (forward/reverse) }\end{array}$} & $\begin{array}{c}\text { BLASTn score - } \\
\text { E-value } \\
\text { (forward/reverse) }\end{array}$ & $\begin{array}{c}\text { Size } \\
\text { of } \\
\text { amplicon }\end{array}$ & $\begin{array}{c}\text { Location of } \\
\text { the primers } \\
\text { (forward/reverse) }\end{array}$ \\
\hline BCRP & NM_004827 & $\begin{array}{l}\text { TGGCTGTCATGGCTTCAGTA/ } \\
\text { GCCACGTGATTCTTCCACAA }\end{array}$ & $40.1-0.015 / 40.1-0.015$ & $206 \mathrm{bp}$ & $1690-1709 / 1895-1876$ \\
MRP3 & NM_003786 & $\begin{array}{l}\text { CCAAGCACATCTTTGACCACG/ } \\
\text { CCTCTGCACCTTCCAACGC }\end{array}$ & $42.1-0.005 / 38.2-0.038$ & $263 \mathrm{bp}$ & 2357-2377/2617-2599 \\
AIMP1 & NM_004757 & $\begin{array}{l}\text { TGCTTTCCCAGGAGAGCC/ } \\
\text { CACCTCAAAGGGAACTCCTTTG }\end{array}$ & $36.1-0.15 / 44.1-0.001$ & $124 \mathrm{bp}$ & $762-779 / 885-865$ \\
\hline
\end{tabular}

of $25 \mu$ l. Reactions were pipetted in semi-skirted 96-well plates (Eppendorf AG) and sealed with optical adhesive PCR film (Eppendorf AG). For BCRP expression analysis, denaturation was performed at $95^{\circ} \mathrm{C}$ for $10 \mathrm{~min}$, followed by 40 PCR cycles with the following specifications: $95^{\circ} \mathrm{C}$ for $30 \mathrm{sec}, 60^{\circ} \mathrm{C}$ for $1 \mathrm{~min}$. For MRP3 expression analysis, denaturation was performed at $95^{\circ} \mathrm{C}$ for $10 \mathrm{~min}$, followed by 40 PCR cycles with the following specifications: $95^{\circ} \mathrm{C}$ for $15 \mathrm{sec}, 60^{\circ} \mathrm{C}$ for $20 \mathrm{sec}, 72^{\circ} \mathrm{C}$ for $20 \mathrm{sec}$. No template controls (NTCs) were included in all the assays. At the end of each RT-qPCR experiment, a dissociation curve was generated using the following thermal profile: $95^{\circ} \mathrm{C}$ for $1 \mathrm{~min}, 55^{\circ} \mathrm{C}$ for $30 \mathrm{sec}, 95^{\circ} \mathrm{C}$ for $30 \mathrm{sec}$ to test for the specificity of each assay. The PCR amplification efficiencies were determined under the same experimental conditions by generating a standard curve as previously described (20). The standard curve was generated by using a 5-point dilution series prepared from a pool of 3 bladder tumor sample cDNA. The slope of the standard curve was used to calculate the PCR amplification efficiency according to:

$$
\text { Efficiency }=\left[10^{(-1 / \text { slope })}\right]-1
$$

PCR amplification efficiency for the BCRP and AIMP1 were $109.5 \%$ and $96.7 \%$, respectively, when using the SYBR Green PCR Master Mix (Applied Biosystems) (Fig. 1A) while that for the MRP3 and AIMP1 was $108.5 \%$ and $104.3 \%$, respectively, when using the QuantiFast SYBR Green PCR Master Mix (Qiagen) (Fig. 1B).

RT-qPCR data analysis. MxPro quantitative real-time PCR software version 4.01 (Stratagene) was used for RT-qPCR data analysis. Inter-experiment control reactions were included in all the assays. The threshold in each assay was manually adjusted so that these control reactions have the same $\mathrm{Cq}$ values in all the experiments (21), taking into consideration that the threshold is in the exponential phase of the PCR. Before choosing to treat replicates collectively (averaging their $\mathrm{Cq}$ values by the machine's software) replicates were examined so that all replicates were within $0.5 \mathrm{Cq}$ of each other (22). In all the reactions, the melting/dissociation curves showed a single melting peak corresponding to the melting temperature (Tm) of the specific amplicon (Fig. 2A). The NTCs reported no $\mathrm{Cq}$ values or melting peaks from the dissociation/melting curves
(Fig. 2A). The specificity of each assay was further verified on $1 \%$ agarose gels (Fig. 2B). The amplification behavior of the AIMP1 was comparable to that of the BCRP and MRP3. The AIMP1 was tested in 15 specimens representing the different histotypes, grades and stages of bladder cancer against $\beta$-actin, a commonly used reference gene in various studies on bladder cancer and its expression was found to be stable.

Gene expression quantification and statistical analysis. The relative mRNA expression of BCRP and MRP3 was calculated using the efficiency-adjusted $\Delta \Delta \mathrm{Cq}$ method as previously described (20). The Relative expression ratios were calculated from the Pfaffl's equation:

$$
R=\frac{\left(E_{\text {target }}\right)^{\Delta C t_{\text {target }}(\text { control }- \text { unknown })}}{\left(E_{\text {reference }}\right)^{\Delta C t_{\text {reference }}(\text { control }- \text { unknown })}}
$$

The efficiency-adjusted $\Delta \Delta \mathrm{Cq}$ method for the calculation of relative expression ratios $(\mathrm{R})$ takes into consideration the difference between PCR amplification efficiency (E) of the target gene and the reference gene. Expression of the drug transporters in the bladder cancer specimen were compared to control/calibrator samples. The controls/calibrators were two normal bladder cDNA samples reverse transcribed from human bladder total RNA purchased from two suppliers; Ambion, Inc. (1 subject) and Clontech Laboratories, Inc. (20 subjects). Relative expression ratios against these two calibrators were averaged according to:

$$
R(\text { average })=[R(\text { ambion })+(R(\text { clontech }) \times 20)] / 21
$$

The log transform of relative expression ratios were used in the statistical analysis. Data were tested for normality using the Kolmogorov and Smirnov normality test. Extreme outliers were tested using the Grubb's test at $\mathrm{P}=0.01$, as described in the International Standard Organization document ISO 5725-2 (23). The two-tail one-sample t-test was used to test for significant difference in BCRP and MRP3 mRNA expression in cancer versus normal bladder tissue. The relation between the relative BCRP and MRP3 mRNA expression and tumor histological type, grade, and stage were investigated using the parametric two-tail unpaired t-test, or one-way ANOVA 
A

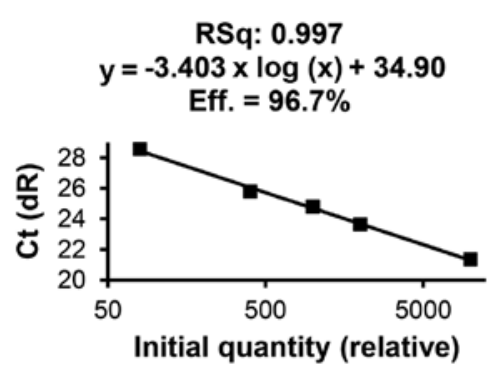

B

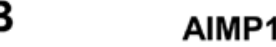

RSq: 0.993

$y=3.224 x \log (x)+35.49$

Eff. $=104.3 \%$

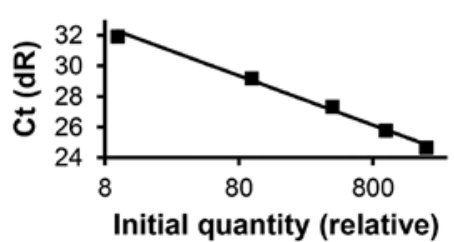

BCRP

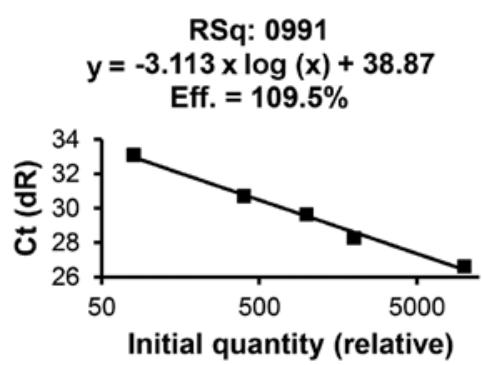

MRP3

RSq: 0.998

$y=3.134 x \log (x)+31.22$

Eff. $=108.5 \%$

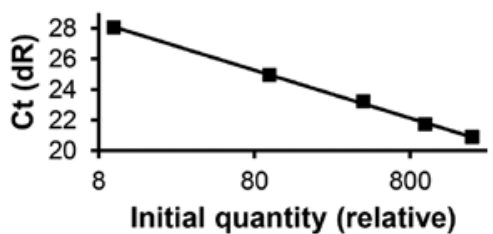

Figure 1. (A) The standard curves for BCRP (left) and AIMP1 (right), using the SYBR Green PCR Master Mix. (B) The standard curves for the AIMP1 (left) and MRP3 (right), using the QuantiFast SYBR Green PCR Master Mix. The initial quantity (relative) of target (x-axis) is plotted against the cycle number (y-axis). The dilution series was composed of five points. These graphs were generated using MX3005 $\mathrm{P}^{\mathrm{TM}} \mathrm{QPCR}$ machine and MxPro software version 4.01.

when appropriate. The interrelationship between BCRP and MRP3 was tested using Pearson correlation $\left(r_{p}\right)$. All the statistical tests were performed using the GraphPad Prism version 5.00 for Windows, GraphPad Software, San Diego, CA, USA (www.graphpad.com). A difference was considered statistically significant at $\mathrm{P}<0.05$.

\section{Results}

Malignancy characterization. The characteristics of the bladder cancer patients with respect to age and sex are summarized in Table II. Moreover, the overview summarizes patient statistics during a 2 months period at the National Cancer Institute-Cairo University, showing that the majority of incoming patients were male. Data given in Table II also include the pathophysiological characteristics for resected tissues: histological type, grade, and invasiveness of their bladder neoplasms. In 6 out of 44 patients undergoing transurethral resection of bladder tumors, no evidence for malignancy was detected through histopathology. In 2 tissue samples with SCC, indications for bilharzia infections were detected, i.e., Schistosoma eggs were present.

BCRP and MRP3 mRNA expression. mRNA expression of BCRP was quantified in 44 bladder tumor specimens relative to normal bladder tissue represented as two normal bladder cDNA samples reverse transcribed from human bladder total RNA purchased from two suppliers; Ambion, Inc. (1 subject) and Clontech Laboratories, Inc. (20 subjects). Histopathological examination revealed that 6 of the 44 specimens collected had no evidence of malignancy. In $95 \%$ of the bladder cancer specimens (36 of 38 specimens), the BCRP
mRNA expression was less than in normal bladder tissue (log relative expression ratio $<0$ ). The decreased expression of BCRP was statistically significant; mean: $-0.6832 \pm 0.07950$, 95\% CI: -0.8443 to $-0.5220, \mathrm{P}<0.0001$. This means that $\mathrm{BCRP}$ mRNA expression was decreased to $\sim 1 / 5$ on average, relative to normal bladder tissue. The MRP3 expression was measured in 36 of the 38 bladder cancer specimens. In $97 \%$ of the bladder cancer specimens (35 of 36 specimens), the MRP3 expression was higher than in normal bladder tissue (log relative expression ratio $>0$ ). The increased expression of MRP3 was also statistically significant; mean: $1.117 \pm 0.09456,95 \%$ CI: 0.9245 to $1.309, \mathrm{P}<0.0001$. This means that MRP3 mRNA expression was increased to $\sim 13$-fold on average compared to normal bladder tissue. Fig. 3 summarizes the pattern of expression of BCRP and MRP3 mRNA in bladder cancer specimens as well as specimens with no evidence of malignancy. Analysis with regard to the potential interrelationship between BCRP and MRP3 revealed that the BCRP mRNA levels were not related to those of MRP3; $r_{p}=0.1245, \mathrm{P}=0.4693$ (Fig. 4).

BCRP and MRP3 mRNA expression versus histopathological parameters of bladder cancer. The various pathological processes, as characterized via the given histological parameters, that could affect the decreased or increased expression of BCRP or MRP3, respectively, were biometrically investigated by employing multivariate analysis. The first parameter tested is the bladder tumor histotype; TCC or SCC of the bladder. Only specimens with pure TCC or SCC phenotype were included in this analysis. The relative expression of BCRP mRNA was similar in TCC and SCC of the bladder cancer specimens as determined by two-tail unpaired t-test; $P=0.1072$. The relative expression of MRP3 mRNA was, however, significantly 
A

AIMP1

$\mathrm{Tm}=79.3^{\circ} \mathrm{C}$

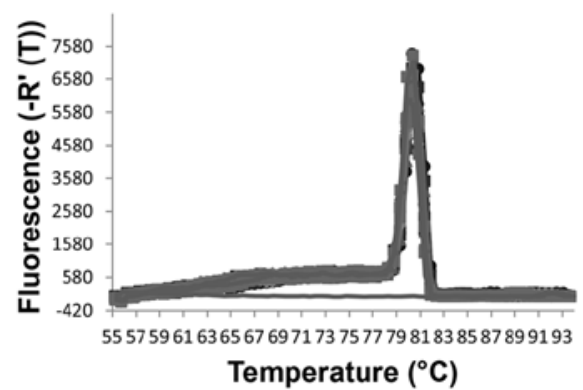

B

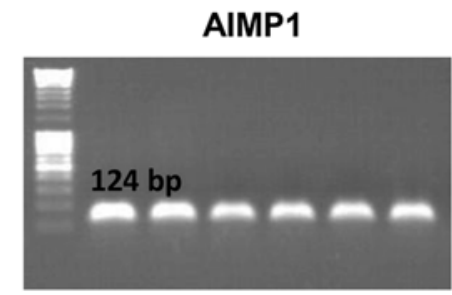

BCRP

$\mathrm{Tm}=80.3^{\circ} \mathrm{C}$

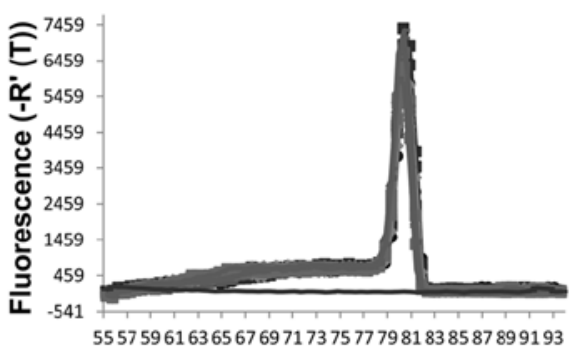

Temperature $\left({ }^{\circ} \mathrm{C}\right)$

BCRP

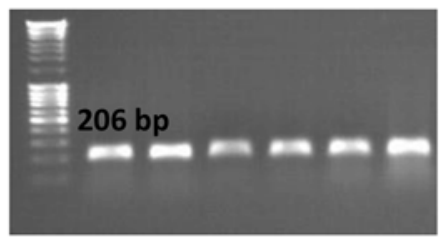

MRP3

$\mathrm{Tm}=88.7^{\circ} \mathrm{C}$

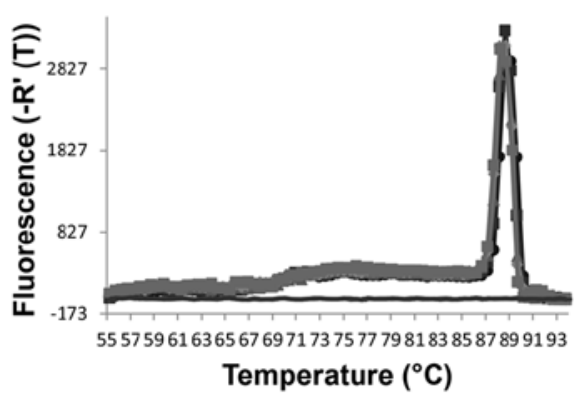

MRP3

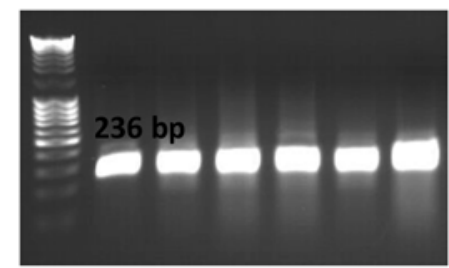

Figure 2. Dissociation curves for AIMP1, BCRP, and MRP3 (A), each showing a single melting peak corresponding to the Tm of the amplified PCR product. The no template controls (NTC) show no melting peaks. These graphs were generated using MX3005 $\mathrm{P}^{\mathrm{TM}} \mathrm{QPCR}$ machine and MxPro software version 4.01. Agarose gels of the RT-qPCR products (B) showing a single band corresponding to the correct size of the amplified PCR products.

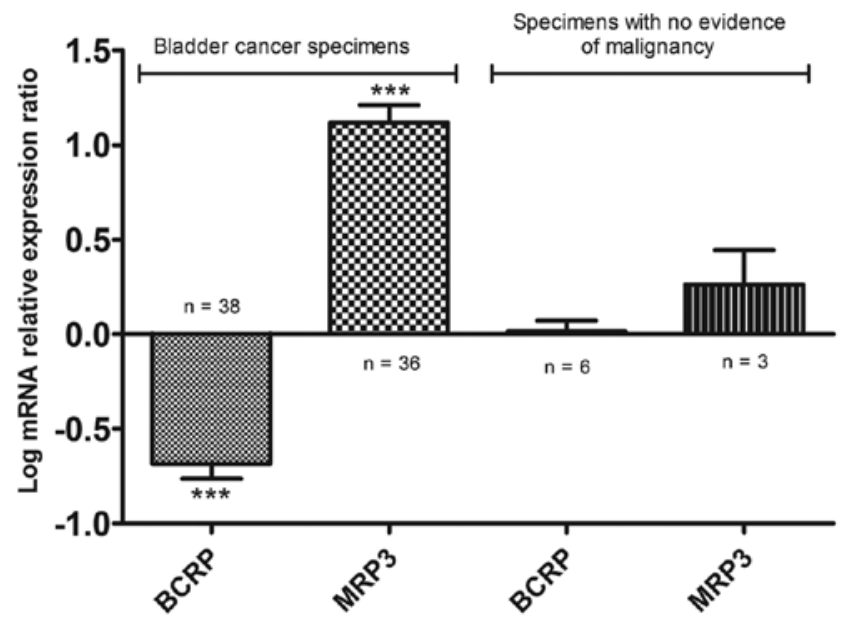

Figure 3. mRNA expression of BCRP and MRP3 represented as log relative expression ratios in bladder cancer specimens relative to normal bladder tissue. Log relative expression ratio equals to zero means similar expression in bladder cancer and normal bladder tissue. ${ }^{* * * *} \mathrm{P}<0.001$.

higher in TCC than in SCC of the bladder cancer specimens; $\mathrm{P}=0.0101$. Fig. 5 summarizes the pattern of expression of BCRP and MRP3 mRNA in TCC vs. SCC of the bladder.

The second parameter tested is the degree of bladder tumor differentiation or bladder tumor grade; G1, G2, G3. The decreased expression of BCRP mRNA was not related to the degree of bladder tumor differentiation (G1, G2, and G3); $\mathrm{P}=0.1808$, nor was the increased expression of MRP 3 mRNA to the degree of bladder tumor differentiation; $\mathrm{P}=0.3465$. Fig. 6 summarizes the comparison of BCRP and MRP3 mRNA expression to bladder tumor grade; G1, G2, and G3.

The third parameter tested is the invasiveness of bladder tumor; superficial (Ta/Tis/T1) vs. muscle-invasive ( $>\mathrm{T} 1)$ bladder

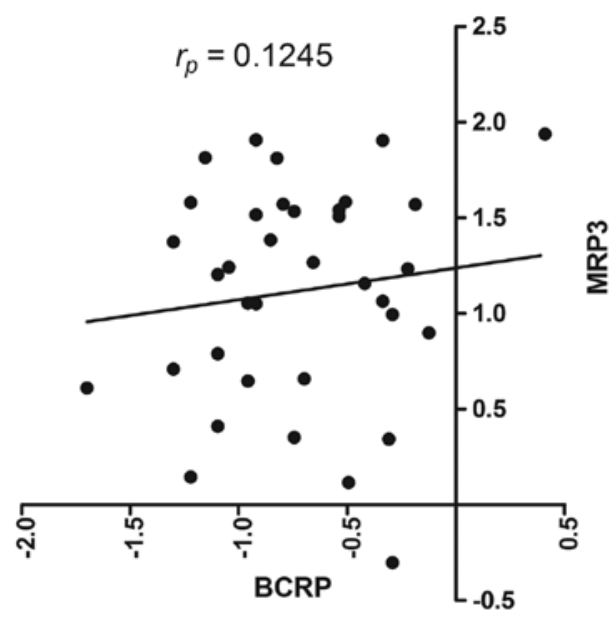

Figure 4. The correlation between BCRP and MRP3 mRNA relative expression in bladder cancer specimens.

tumors. The expression of BCRP mRNA was similar in superficial $(\mathrm{Ta} / \mathrm{Tis} / \mathrm{T} 1)$ and muscle-invasive $(>\mathrm{T} 1)$ bladder tumors; $\mathrm{P}=0.8016$. The expression of MRP3 mRNA was, however, significantly higher in superficial than in invasive bladder tumors; $\mathrm{P}=0.0173$. Fig. 7 summarizes the comparison of BCRP and MRP3 mRNA expression to the invasiveness of bladder tumor.

\section{Discussion}

Being expressed at the epithelial barriers of several tissues, $\mathrm{ABC}$ transporters are believed to be a component of the lines of defense of tissues by actively effluxing toxic endobiotics and xenobiotics out of cells $(7,9,14,24)$. On the other hand, overex- 

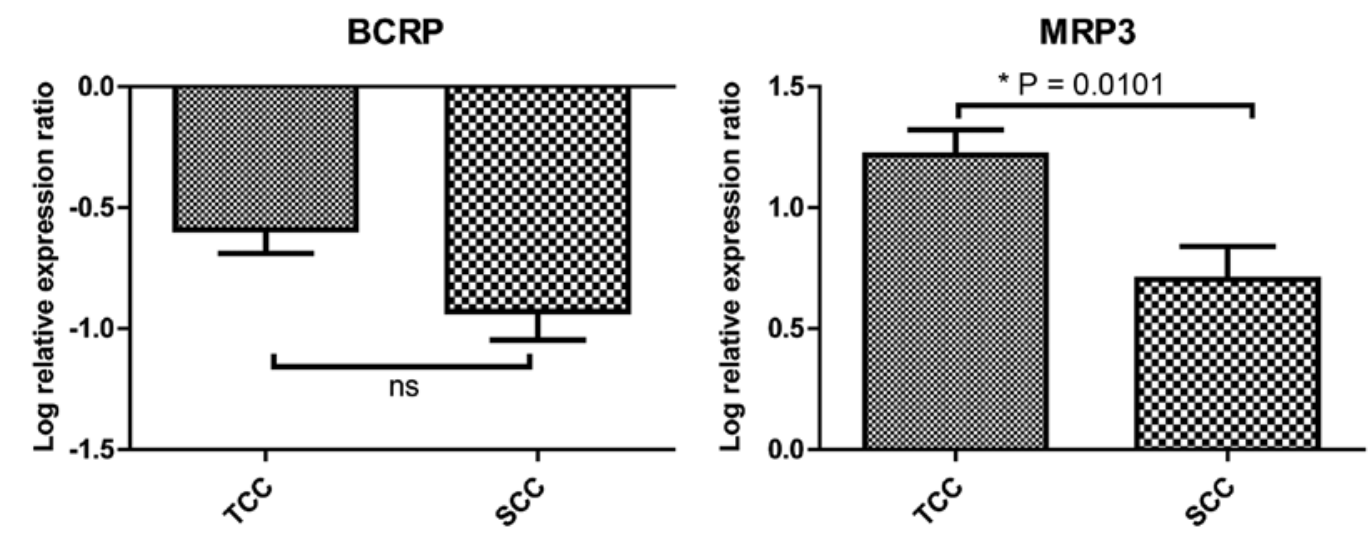

Figure 5. mRNA expression of BCRP and MRP3 in TCC and SCC of the bladder represented as log relative expression ratios in bladder cancer specimens relative to normal bladder tissue.

Table II. Clinical characteristics of bladder cancer patients

\begin{tabular}{lc}
\hline Characteristics of bladder cancer patients & $\begin{array}{c}\text { No. of } \\
\text { patients }\end{array}$ \\
\hline Total number of patients & 44 \\
A) No. of patients with evidence of malignancy & 38 \\
Age & \\
S40 & 4 \\
$>40-55$ & 10 \\
$>55-70$ & 19 \\
$>70$ & 5 \\
Sex & \\
Male & 29 \\
Female & 9 \\
Histology & \\
Urothelial/Transitional cell carcinoma (TCC) & 28 \\
Squamous cell carcinoma (SCC) & 7 \\
Mixed TCC and SCC & 1 \\
Adenocarcinoma & 1 \\
Undifferentiated carcinoma & 1 \\
Histological grade & \\
G1 & \\
G2 & 6 \\
G3 & 6 \\
Grade could not be assessed & 16 \\
Invasiveness (stage) & 13 \\
Tumor confined to the urothelium only (Ta/Tis) & 4 \\
Invasion to lamina propria only (T1) & \\
Muscle invasion (>T1) & \\
Stage could not be assessed & \\
B) No. of patients with no evidence of malignancy & 6 \\
\hline & \\
\hline
\end{tabular}

pression of $\mathrm{ABC}$ transporters in cancer cell lines is associated with resistance to a variety of commonly used chemotherapeutic agents $(9,25,26)$, a phenomenon which directed several studies to investigate the relevance of $\mathrm{ABC}$ transporters in clinical MDR. However, to ascertain their relevance in clinical MDR, studies investigating the expression of ABC transporters in specific tumor types are still needed (27-30). In addition, there are very few studies examining the expression of $\mathrm{ABC}$ transporters in native (untreated) cancer tissues making the potential role that $\mathrm{ABC}$ transporters play in the pathophysiology of cancer and/or clinical MDR still unknown (16).

Of interest, BCRP and MRP3 are expressed at the transitional epithelium of normal bladder. However, their expression data in primary TCC and SCC bladder tumors are still lacking. In the present study we measured the mRNA levels of MRP3 and BCRP in untreated primary bladder tumors compared to normal bladder tissue using RT-qPCR. Furthermore, the relative mRNA expression in the two major histotypes of bladder cancer; TCC and SCC were compared. In addition, the association between the mRNA expression and tumor characteristics of grade (degree of tumor differentiation) and stage (invasiveness of bladder tumor) were investigated. RT-qPCR is considered the prime technique and the method of choice to measure differential gene expression $(20,31,32)$. Its high sensitivity enables the detection of small differences in mRNA expression that other commonly used methods such as immunohistochemistry or western blotting would fail to, as in cases of measuring gene expression of ABC transporters (33-35). The levels of BCRP mRNA were previously reported to be consistent with the protein expression as determined by western blot analysis in head and neck squamous cell carcinoma cell lines (36). Similar observation was shown when MRP3 protein levels were analyzed in breast cancer by immunohistochemistry (37).

Downregulation of BCRP $m R N A$. Significant downregulation of BCRP was detected in bladder cancer compared to normal bladder tissue in the current study. Although BCRP mRNA expression in SCC of the bladder was lower than that in TCC of the bladder, the difference between cell types was not statistically significant. This clearly indicates that downregulation of BCRP in bladder cancer occurs in general, irrespective of the histological type of the tumor. Previous studies investigating the expression of BCRP in bladder cancer documented no or very weak expression of the BCRP protein $(38,39)$. In another study on the expression of BCRP in locally advanced bladder cancer, positive immunohistochemical staining of BCRP protein was 
BCRP

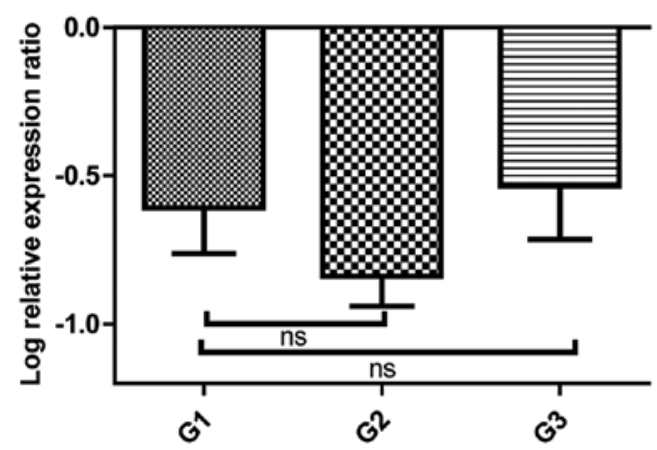

MRP3

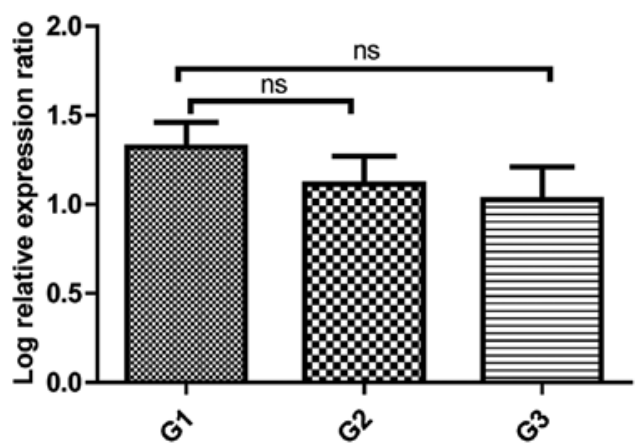

Figure 6. mRNA expression of BCRP and MRP3 in the different grades of bladder tumors (G1, G2 and G3) represented as log relative expression ratios in bladder cancer specimens relative to normal bladder tissue.

BCRP

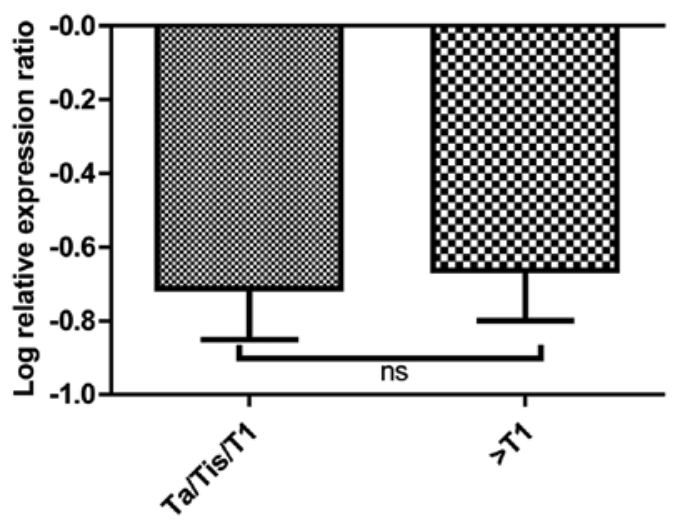

MRP3

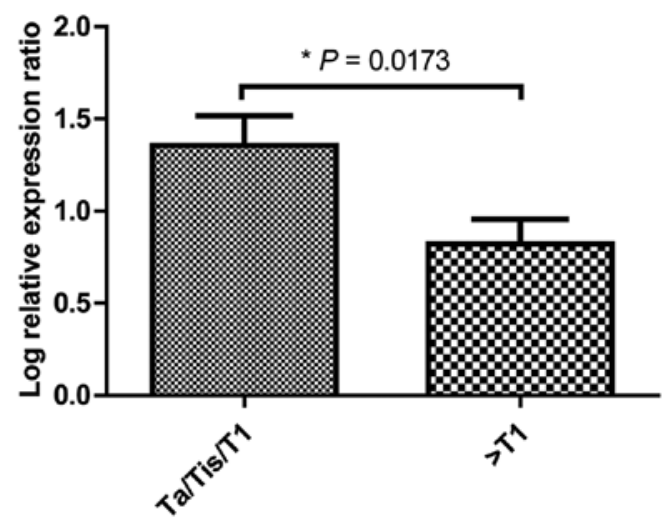

Figure 7. mRNA expression of BCRP and MRP3 in the superficial (Ta/Tis/T1) and muscle-invasive (>T1) bladder tumors represented as log relative expression ratios in bladder cancer specimens relative to normal bladder tissue.

found in only $23(28 \%)$ of 82 patients and expression was not associated with the therapeutic outcome (40). Doyle and Ross detected mRNA expression of BCRP in normal bladder tissue using a commercially available dot blot that contained RNA from 50 human tissues (7). In addition, Fetsch et al confirmed the localization of BCRP protein at the transitional epithelium of normal bladder (14). To our best knowledge, this is the first study to report decreased expression of BCRP mRNA in the different histotypes of untreated bladder tumors relative to normal bladder tissue.

Previously, low mRNA levels of BCRP were documented in breast cancer $(41,42)$. In addition, immunohistochemical staining of breast cancer tissues revealed positive staining in normal duct cells versus no staining in carcinoma cells (41). In addition, BCRP mRNA expression was significantly lower (approximately 100-fold) in tumoral colon tissue compared to the normal colon (43). Using immunohistochemistry, strong BCRP staining was observed in only 11 of 41 gallbladder carcinoma specimens, while the majority of the normal and cholelithiasis samples showed intense staining (44). In addition, BCRP mRNA and protein were decreased several-fold in human colorectal cancer tissues as well as in cervical cancer tissues in comparison to their matched normal tissues (16); a result that drove the investigators to examine BCRP expression using a commercial array of cDNA from 19 different cancer tissues, including bladder cancer, paired with their matched cDNA from normal tissue from the same patient. Significant downregulation was observed in breast, ovarian, lung, kidney, liver, prostate, uterine, rectal, thyroid, testicular, as well as colon and cervical cancer (16); a result that led the investigators to hypothesize that downregulation of BCRP is a widespread phenomenon in human cancers. In contrast to our finding that BCRP is downregulated in bladder cancer, the study of Gupta et al showed no significant difference in BCRP mRNA expression between cancer and normal bladder tissue (16). However, the number of bladder cancer samples in the cDNA array hybridization used in their study was only 5 samples compared to 38 bladder cancer samples included in our study, besides the high sensitivity of quantitative real-time PCR compared to array hybridization (45). Taken together and in addition to our finding that BCRP is downregulated in the different histotypes of bladder cancer, further confirmation of the widespread observed downregulation of BCRP in human cancers can be drawn.

Localization of BCRP protein at the transitional epithelium of normal bladder (14) would decrease cellular accumulation of its substrates of chemical carcinogens, hence, protect the bladder epithelium against chemical-induced carcinogenesis. A variety of chemical carcinogens are known to be transported by BCRP. These include; 2-amino-1-methyl-6-phenylimidazo[4,5- 
b]pyridine (PhIP), 2-amino-3-methylimidazo[4,5-f]quinoline (IQ), 3-amino-1,4-dimethyl-5H-pyrido[4,3-b]indole (Trp-P-1), aflatoxin B1, 2-amino-3,8-dimethylimidazo[4,5-f]quinoxaline (MeIQx), and the sulfate and glucuronide conjugates of benzo[a] pyrene (BP) (46-49). Decreased expression of BCRP in bladder cancer would lead to increased cellular accumulation of such chemical carcinogens increasing DNA damage, mutations, and subsequently increasing malignant transformations.

Given that protoporphyrin IX is a substrate of BCRP (50-52) and is the precursor for heme, downregulation of BCRP would lead to the accumulation of protoporphyrin IX and heme in cancer cells. Increased cellular levels of protoporphyrin IX and heme generates potentially DNA damaging reactive oxygen species (53). Downregulation of BCRP by RNA interference technology and the FTC (a BCRP inhibitor) treatment of embryonic stem cells resulted in increased cellular levels of protoprphyrin IX and reactive oxygen species (53). Moreover, DNA damage signals were triggered suggesting that enforced downregulation of BCRP in embryonic stem cells resulted in DNA damage as a result of the increased cellular levels of reactive oxygen species (53). In addition, heme is a cofactor for the product of the $i N O S$ gene; the inducible nitric oxide synthase. Inducible nitric oxide synthase utilizes arginine to synthesize nitric oxide (NO). Previously, it has been demonstrated that malignancy is associated with overexpression of the $i N O S$ gene inducing oxidative stress through the overproduction of nitric oxide $(54,55)$. Therefore, downregulation of BCRP may provide an explanation for the increased availability of heme required for the increased activity of inducible nitric oxide synthase in cancer cells. NO can damage DNA and itself induces angiogenesis therefore has the potential to promote tumor development, growth, as well as invasiveness and metastatic ability (55).

In our study, decreased BCRP mRNA expression was not associated with high grade or invasive bladder tumors suggesting that decreased BCRP mRNA expression can rather be an early event in bladder tumorigenesis. The most intensively investigated solid tumor type was breast cancer $(33,41,42)$. Similar to our results Burger et al documented no association between BCRP mRNA expression and tumor grade or stage of breast cancer (33). Similarly, Kanzaki et al reported that BCRP mRNA expression was independent of tumor stage (42). In contrast, Faneyte et al reported that high tumor malignancy grade was associated with decreased BCRP mRNA expression in breast cancer (41). In pancreatic carcinoma, there was no correlation of the mRNA expression level to carcinoma stages or grades (56).

Upregulation of MRP3 $m R N A$. Herein, we also report overexpression of MRP3 in bladder cancer compared to normal bladder tissue. Consistent with previous studies, MRP3 is expressed in normal bladder tissue (12). The increased expression of MRP3 in primary untreated bladder tumors was previously reported where MRP3 showed the highest expression among the other ABC transporters, MDR1, MRP1, and MRP2 (57). MRP3 might be involved in the membrane transport of endogenous substrates, in normal and cancerous bladder tissues. Expression of MRP3 at the transitional epithelium of normal bladder is consistent with the cytoprotective role $\mathrm{ABC}$ transporters play by effluxing xenobiotics and their metabolites out of cells. Gene amplification of MRP3 in cancer cells in vitro, as previously reported (58), provides an explanation for the increased expression of MRP3 in bladder cancer.

It was previously reported that MRP3 is frequently amplified and overexpressed in primary breast cancer (37). The MRP3 expression was significantly higher in non-muscle invasive (Ta/Tis/T1) than in muscle invasive bladder tumors $(>\mathrm{T} 1)$, suggesting that MRP3 expression is regulated differently in the two classes of bladder tumors. However, the increased MRP3 expression was not correlated to the decreased BCRP expression. Therefore, the aberrant expression of the two transporters appears to be two unrelated phenomena in bladder cancer. However, since BCRP is downregulated in $95 \%$ of the samples and MRP3 is upregulated in 97\%, the possibility that MRP3 expression compensates for the defective BCRP expression is worth further investigation. Several studies reported the ability of MRP3 to confer overlapping but distinct patterns of MDR in cancer cells when overexpressed compared to BCRP $(9,59,60)$. MRP3 was shown to be capable to decrease cellular accumulation of methotrexate, etoposide, teniposide, vencristin, cisplatin and doxorubicin $(9,59,60)$. Therefore, increased expression of MRP3 in bladder cancer could provide an explanation of intrinsic clinical MDR. The expression of MRP3 was significantly higher in TCC than in SCC of the bladder suggesting that MRP3 could decrease cellular drug accumulation of MRP3 substrates used in the chemotherapeutic regimens for treatment of TCC of the bladder.

Potential impact of expression profiles on cytotoxic therapies. Previously, it has been reported that BCRP plays a role in the maintenance of cellular folate homeostasis (61) by its unique capability to export mono-, di-, and triglutamates of folates out of cells $(62,63)$. In contrast, other ABC transporters (MRP1 through MRP4) have restricted ability to export only monoglutamate forms of folates. Cellular retention of folates is aided by the addition of glutamate residues by the folylpoly- $\gamma$-glutamate synthase (FPGS) enzyme (64). Neoplastic dividing cells have an absolute requirement for reduced folates, in order to properly initiate and complete DNA replication and mitosis. This is due to the fact that reduced folate cofactors play a key role in onecarbon transfer reactions in the de novo biosynthesis of purines and thymidylate. Ifergan et al showed that downregulation of BCRP expression and efflux activity is an essential component of cellular survival under conditions of folate deficiency (61). Thus, in the context of malignancy, downregulation of BCRP is consistent with the need to increase cellular retention of folates to support the requirements of the rapidly dividing cancer cells for DNA synthesis.

Of interest, methotrexate which is commonly used in drug combination regimens for treatment of bladder cancer has a susceptibility to polyglutamation. The ability of MRP3 to export polyglutamed forms of methotrexate is limited (65). This suggests that bladder cancer would respond optimally to anticancer regimens including methotrexate. The fact that polyglutamation of methotrexate results in massive enhancement of cytotoxicity is consistent with our finding that BCRP is downregulated while MRP3 is upregulated in bladder cancer. Therefore, polyglutamated methotrexate will be retained into the cells and the increased MRP3 expression will not compensate for the decreased BCRP expression in effluxing polyglutamated methotrexate. 
In conclusion, bladder cancer is associated with perturbed expression of BCRP and MRP3. BCRP expression is decreased in TCC and SCC of the bladder with no significant difference between the two histotypes of bladder tumors. MRP3 expression is, however, increased in TCC and SCC of the bladder with TCC expressing MRP3 at significantly higher levels than SCC. The manner in which the two transporters are aberrantly regulated in bladder cancer needs further investigation. Whether this aberrant expression has the potential to affect therapeutic outcome of cancer chemotherapy needs further investigation as well. Moreover, the aberrant expression of BCRP could be linked to the pathogenesis of bladder cancer.

\section{Acknowledgements}

This project was funded by the German University in Cairo (GUC). The Stratagene QPCR machine was funded by the German Academic Exchange Service (DAAD). The authors would like to thank Roland Varecka from Boehringer Ingelheim, Austria for the excellent training and valuable technical advice on performing RT-qPCR experiments. The authors would also like to thank Mohamed Abdulmonem for the excellent technical assistance.

\section{References}

1. Parkin DM, Bray F, Ferlay J and Pisani P: Global cancer statistics, 2002. CA Cancer J Clin 55: 74-108, 2005.

2. Scélo G and Brennan P: The epidemiology of bladder and kidney cancer. Nat Clin Pract Urol 4: 205-217, 2007.

3. Parkin DM: The global burden of urinary bladder cancer. Scand J Urol Nephrol (Suppl) 218: 12-20, 2008.

4. Felix AS, Soliman AS, Khaled H, Zaghloul MS, Banerjee M, El-Baradie M, El-Kalawy M, Abd-Elsayed AA, Ismail K, Hablas A, et al: The changing patterns of bladder cancer in Egypt over the past 26 years. Cancer Causes Control 19: 421-429, 2008

5. Gottesman MM, Fojo T and Bates SE: Multidrug resistance in cancer: Role of ATP-dependent transporters. Nat Rev Cancer 2: 48-58, 2002.

6. Chen Z, Shi T, Zhang L, Zhu P, Deng M, Huang C, Hu T, Jiang L and Li J: Mammalian drug efflux transporters of the ATP binding cassette $(\mathrm{ABC})$ family in multidrug resistance: A review of the past decade. Cancer Lett 370: 153-164, 2016.

7. Doyle L and Ross DD: Multidrug resistance mediated by the breast cancer resistance protein BCRP (ABCG2). Oncogene 22 : 7340-7358, 2003.

8. Kruh GD, Belinsky MG, Gallo JM and Lee K: Physiological and pharmacological functions of Mrp2, Mrp3 and Mrp4 as determined from recent studies on gene-disrupted mice. Cancer Metastasis Rev 26: 5-14, 2007.

9. Kool M, van der Linden M, de Haas M, Scheffer GL, de Vree JM, Smith AJ, Jansen G, Peters GJ, Ponne N, Scheper RJ, et al: MRP3, an organic anion transporter able to transport anti-cancer drugs. Proc Natl Acad Sci USA 96: 6914-6919, 1999.

10. Kiuchi Y,Suzuki H,Hirohashi T, Tyson CA and Sugiyama Y: cDNA cloning and inducible expression of human multidrug resistance associated protein 3 (MRP3). FEBS Lett 433: 149-152, 1998.

11. Belinsky MG, Bain LJ, Balsara BB, Testa JR and Kruh GD: Characterization of MOAT-C and MOAT-D, new members of the $\mathrm{MRP} / \mathrm{cMOAT}$ subfamily of transporter proteins. J Natl Cancer Inst 90: 1735-1741, 1998.

12. Kool M, de Haas M, Scheffer GL, Scheper RJ, van Eijk MJ, Juijn JA, Baas F and Borst P: Analysis of expression of cMOAT (MRP2), MRP3, MRP4, and MRP5, homologues of the multidrug resistance-associated protein gene (MRP1), in human cancer cell lines. Cancer Res 57: 3537-3547, 1997.

13. Mo W and Zhang JT: Human ABCG2: Structure, function, and its role in multidrug resistance. Int J Biochem Mol Biol 3: 1-27, 2012.

14. Fetsch PA, Abati A, Litman T, Morisaki K, Honjo Y, Mittal K and Bates SE: Localization of the ABCG2 mitoxantrone resistanceassociated protein in normal tissues. Cancer Lett 235: 84-92, 2006.
15. Polli JW, Olson KL, Chism JP, John-Williams LS, Yeager RL, Woodard SM, Otto V, Castellino S and Demby VE: An unexpected synergist role of P-glycoprotein and breast cancer resistance protein on the central nervous system penetration of the tyrosine kinase inhibitor lapatinib ( $\mathrm{N}-\{3$-chloro-4-[(3fluorobenzyl)oxy]phenyl $\}-6-[5-(\{[2-($ methylsulfonyl)ethyl $]$ amino\}methyl)-2-furyl]-4-quinazolinamine; GW572016). Drug Metab Dispos 37: 439-442, 2009.

16. Gupta N, Martin PM, Miyauchi S, Ananth S, Herdman AV, Martindale RG, Podolsky R and Ganapathy V: Down-regulation of BCRP/ABCG2 in colorectal and cervical cancer. Biochem Biophys Res Commun 343: 571-577, 2006.

17. van den Heuvel-Eibrink MM, Wiemer EA, Prins A, Meijerink JP Vossebeld PJ, van der Holt B, Pieters R and Sonneveld P: Increased expression of the breast cancer resistance protein (BCRP) in relapsed or refractory acute myeloid leukemia (AML). Leukemia 16: 833-839, 2002

18. Kielar D, Kaminski WE, Liebisch G, Piehler A, Wenzel JJ, Möhle C, Heimerl S, Langmann T, Friedrich SO, Böttcher A, et al: Adenosine triphosphate binding cassette (ABC) transporters are expressed and regulated during terminal keratinocyte differentiation: A potential role for ABCA7 in epidermal lipid reorganization. J Invest Dermatol 121: 465-474, 2003.

19. Ussar S and Voss T: MEK1 and MEK2, different regulators of the G1/S transition. J Biol Chem 279: 43861-43869, 2004.

20. Pfaffl MW: A new mathematical model for relative quantification in real-time RT-PCR. Nucleic Acids Res 29: e45, 2001.

21. Hellemans J, Mortier G, De Paepe A, Speleman F and Vandesompele J: qBase relative quantification framework and software for management and automated analysis of real-time quantitative PCR data. Genome Biol 8: R19, 2007.

22. Nolan T, Hands RE and Bustin SA: Quantification of mRNA using real-time RT-PCR. Nat Protoc 1: 1559-1582, 2006.

23. Burns MJ, Nixon GJ, Foy CA and Harris N: Standardisation of data from real-time quantitative PCR methods - evaluation of outliers and comparison of calibration curves. BMC Biotechnol 5: $31,2005$.

24. Maliepaard M, Scheffer GL, Faneyte IF, van Gastelen MA, Pijnenborg AC, Schinkel AH, van De Vijver MJ, Scheper RJ and Schellens JH: Subcellular localization and distribution of the breast cancer resistance protein transporter in normal human tissues. Cancer Res 61: 3458-3464, 2001.

25. Doyle LA, Yang W, Abruzzo LV, Krogmann T, Gao Y, Rishi AK and Ross DD: A multidrug resistance transporter from human MCF-7 breast cancer cells. Proc Natl Acad Sci USA 95: 15665-15670, 1998.

26. Miyake K, Mickley L, Litman T, Zhan Z, Robey R, Cristensen B, Brangi M, Greenberger L, Dean M, Fojo T, et al: Molecular cloning of cDNAs which are highly overexpressed in mitoxantrone-resistant cells: Demonstration of homology to $\mathrm{ABC}$ transport genes. Cancer Res 59: 8-13, 1999.

27. Robey RW, Polgar O, Deeken J, To KW and Bates SE: ABCG2: Determining its relevance in clinical drug resistance. Cancer Metastasis Rev 26: 39-57, 2007.

28. Robey RW, To KK, Polgar O, Dohse M, Fetsch P, Dean M and Bates SE: ABCG2: A perspective. Adv Drug Deliv Rev 61: 3-13, 2009.

29. Mao Q and Unadkat JD: Role of the breast cancer resistance protein (ABCG2) in drug transport. AAPS J 7: E118-E133, 2005.

30. Natarajan K, Xie Y, Baer MR and Ross DD: Role of breast cancer resistance protein (BCRP/ABCG2) in cancer drug resistance. Biochem Pharmacol 83: 1084-1103, 2012.

31. Bustin SA, Benes V, Nolan T and Pfaffl MW: Quantitative real-time RT-PCR - a perspective. J Mol Endocrinol 34: 597-601, 2005.

32. Kubista M, Andrade JM, Bengtsson M, Forootan A, Jonák J, Lind K, Sindelka R, Sjöback R, Sjögreen B, Strömbom L, et al: The real-time polymerase chain reaction. Mol Aspects Med 27: 95-125, 2006

33. Burger H, Foekens JA, Look MP, Meijer-van Gelder ME, Klijn JG, Wiemer EA, Stoter G and Nooter K: RNA expression of breast cancer resistance protein, lung resistance-related protein, multidrug resistance-associated proteins 1 and 2, and multidrug resistance gene 1 in breast cancer: Correlation with chemotherapeutic response. Clin Cancer Res 9: 827-836, 2003.

34. Wong ML and Medrano JF: Real-time PCR for mRNA quantitation. Biotechniques 39: 75-85, 2005.

35. Huggett J, Dheda K, Bustin S and Zumla A: Real-time RT-PCR normalisation; strategies and considerations. Genes Immun 6: 279-284, 2005. 
36. Shen B, Dong P, Li D and Gao S: Expression and function of ABCG2 in head and neck squamous cell carcinoma and cell lines. Exp Ther Med 2: 1151-1157, 2011.

37. Partanen L, Staaf J, Tanner M, Tuominen VJ, Borg A and Isola J: Amplification and overexpression of the ABCC3 (MRP3) gene in primary breast cancer. Genes Chromosomes Cancer 51: 832-840, 2012.

38. Diestra JE, Scheffer GL, Català I, Maliepaard M, Schellens JH, Scheper RJ, Germà-Lluch JR and Izquierdo MA: Frequent expression of the multi-drug resistance-associated protein $\mathrm{BCRP} / \mathrm{MXR} / \mathrm{ABCP} / \mathrm{ABCG} 2$ in human tumours detected by the BXP-21 monoclonal antibody in paraffin-embedded material. J Pathol 198: 213-219, 2002.

39. Scheffer GL, Maliepaard M, Pijnenborg AC, van Gastelen MA, de Jong MC, Schroeijers AB, van der Kolk DM, Allen JD, Ross DD, van der Valk P, et al: Breast cancer resistance protein is localized at the plasma membrane in mitoxantrone- and topotecan-resistant cell lines. Cancer Res 60: 2589-2593, 2000.

40. Diestra JE, Condom E, Del Muro XG, Scheffer GL, Pérez J, Zurita AJ, Muñoz-Seguí J, Vigués F, Scheper RJ, Capellá G, et al: Expression of multidrug resistance proteins P-glycoprotein, multidrug resistance protein 1 , breast cancer resistance protein and lung resistance related protein in locally advanced bladder cancer treated with neoadjuvant chemotherapy: Biological and clinical implications. J Urol 170: 1383-1387, 2003.

41. Faneyte IF, Kristel PM, Maliepaard M, Scheffer GL, Scheper RJ, Schellens JH and van de Vijver MJ: Expression of the breast cancer resistance protein in breast cancer. Clin Cancer Res 8: 1068-1074, 2002.

42. Kanzaki A, Toi M, Nakayama K, Bando H, Mutoh M, Uchida T, Fukumoto $\mathrm{M}$ and Takebayashi Y: Expression of multidrug resistance-related transporters in human breast carcinoma. Jpn J Cancer Res 92: 452-458, 2001.

43. Candeil L, Gourdier I, Peyron D, Vezzio N, Copois V, Bibeau F, Orsetti B, Scheffer GL, Ychou M, Khan QA, et al: ABCG2 overexpression in colon cancer cells resistant to SN38 and in irinotecan-treated metastases. Int J Cancer 109: 848-854, 2004.

44. Aust S, Obrist P, Jaeger W, Klimpfinger M, Tucek G, Wrba F, Penner E and Thalhammer T: Subcellular localization of the ABCG2 transporter in normal and malignant human gallbladder epithelium. Lab Invest 84: 1024-1036, 2004.

45. King $\mathrm{HC}$ and Sinha AA: Gene expression profile analysis by DNA microarrays: Promise and pitfalls. JAMA 286: 2280-2288, 2001.

46. van Herwaarden AE, Wagenaar E, Karnekamp B, Merino G, Jonker JW and Schinkel AH: Breast cancer resistance protein (Bcrp1/Abcg2) reduces systemic exposure of the dietary carcinogens aflatoxin B1, IQ and Trp-P-1 but also mediates their secretion into breast milk. Carcinogenesis 27: 123-130, 2006

47. van Herwaarden AE, Jonker JW, Wagenaar E, Brinkhuis RF, Schellens JH, Beijnen JH and Schinkel AH: The breast cancer resistance protein (Bcrp1/Abcg2) restricts exposure to the dietary carcinogen 2-amino-1-methyl-6-phenylimidazo[4,5-b)pyridine. Cancer Res 63: 6447-6452, 2003.

48. Ebert B, Seidel A and Lampen A: Identification of BCRP as transporter of benzo[a)pyrene conjugates metabolically formed in Caco-2 cells and its induction by Ah-receptor agonists Carcinogenesis 26: 1754-1763, 2005

49. Enokizono J, Kusuhara H, Ose A, Schinkel AH and Sugiyama Y Quantitative investigation of the role of breast cancer resistance protein (Bcrp/Abcg2) in limiting brain and testis penetration of xenobiotic compounds. Drug Metab Dispos 36: 995-1002, 2008.
50. Jonker JW, Buitelaar M, Wagenaar E, Van Der Valk MA, Scheffer GL, Scheper RJ, Plosch T, Kuipers F, Elferink RP, Rosing $\mathrm{H}$, et al: The breast cancer resistance protein protects against a major chlorophyll-derived dietary phototoxin and protoporphyria. Proc Natl Acad Sci USA 99: 15649-15654, 2002.

51. Robey RW, Steadman K, Polgar O and Bates SE: ABCG2mediated transport of photosensitizers: Potential impact on photodynamic therapy. Cancer Biol Ther 4: 187-194, 2005.

52. Krishnamurthy P, Ross DD, Nakanishi T, Bailey-Dell K, Zhou S, Mercer KE, Sarkadi B, Sorrentino BP and Schuetz JD: The stem cell marker Bcrp/ABCG2 enhances hypoxic cell survival through interactions with heme. J Biol Chem 279: 24218-24225, 2004.

53. Susanto J, Lin YH, Chen YN, Shen CR, Yan YT, Tsai ST, Chen $\mathrm{CH}$ and Shen $\mathrm{CN}$ : Porphyrin homeostasis maintained by ABCG2 regulates self-renewal of embryonic stem cells. PLoS One 3: e4023, 2008

54. Segawa Y, Oda Y, Yamamoto H, Uryu H, Shiratsuchi H, Hirakawa N, Tomita K, Yamamoto T, Oda S, Yamada T, et al: Overexpression of inducible nitric oxide synthase and accumulation of $8-\mathrm{OHdG}$ in nasopharyngeal carcinoma. Histopathology 52: 213-223, 2008

55. Xu W, Liu LZ, Loizidou M, Ahmed M and Charles IG: The role of nitric oxide in cancer. Cell Res 12: 311-320, 2002.

56. König J, Hartel M, Nies AT, Martignoni ME, Guo J, Büchler MW, Friess H and Keppler D: Expression and localization of human multidrug resistance protein $(\mathrm{ABCC})$ family members in pancreatic carcinoma. Int J Cancer 115: 359-367, 2005.

57. Tada Y, Wada M, Migita T, Nagayama J, Hinoshita E, Mochida Y, Maehara Y, Tsuneyoshi M, Kuwano M and Naito S: Increased expression of multidrug resistance-associated proteins in bladder cancer during clinical course and drug resistance to doxorubicin. Int J Cancer 98: 630-635, 2002.

58. O'Brien C, Cavet G, Pandita A, Hu X, Haydu L, Mohan S, Toy K, Rivers CS, Modrusan Z, Amler LC, et al: Functional genomics identifies ABCC3 as a mediator of taxane resistance in HER2amplified breast cancer. Cancer Res 68: 5380-5389, 2008.

59. Zeng H, Bain LJ, Belinsky MG and Kruh GD: Expression of multidrug resistance protein-3 (multispecific organic anion transporter-D) in human embryonic kidney 293 cells confers resistance to anticancer agents. Cancer Res 59: 5964-5967, 1999.

60. Young LC, Campling BG, Voskoglou-Nomikos T, Cole SP, Deeley RG and Gerlach JH: Expression of multidrug resistance protein-related genes in lung cancer: Correlation with drug response. Clin Cancer Res 5: 673-680, 1999.

61. Ifergan I, Shafran A, Jansen G, Hooijberg JH, Scheffer GL and Assaraf YG: Folate deprivation results in the loss of breast cancer resistance protein (BCRP/ABCG2) expression. A role for BCRP in cellular folate homeostasis. J Biol Chem 279: 25527-25534, 2004.

62. Chen ZS, Robey RW, Belinsky MG, Shchaveleva I, Ren XQ, Sugimoto Y, Ross DD, Bates SE and Kruh GD: Transport of methotrexate, methotrexate polyglutamates, and 17beta-estradiol 17-(beta-D-glucuronide) by ABCG2: Effects of acquired mutations at R482 on methotrexate transport. Cancer Res 63: 4048-4054, 2003.

63. Volk EL and Schneider E: Wild-type breast cancer resistance protein (BCRP/ABCG2) is a methotrexate polyglutamate transporter. Cancer Res 63: 5538-5543, 2003.

64. Hardwick LJ, Velamakanni S and van Veen HW: The emerging pharmacotherapeutic significance of the breast cancer resistance protein (ABCG2). Br J Pharmacol 151: 163-174, 2007.

65. Zeng H, Chen ZS, Belinsky MG, Rea PA and Kruh GD: Transport of methotrexate (MTX) and folates by multidrug resistance protein (MRP) 3 and MRP1: Effect of polyglutamylation on MTX transport. Cancer Res 61: 7225-7232, 2001. 